\title{
ESTUDO DOS DADOS OBTIDOS DE UMA POPULAÇÃO DE BIOMPHALARIA GLABRA TA DE BELO HORIZONTE INFECTADA POR SCHISTOSOMA MANSONI DA MESMA CIDADE, E DE UMA POPULAÇÃO DE B. TENAGOPHILA DE CAMPINAS, INFECTADA POR S. MANSONI DE SÃO JOSÉ DOS CAMPOS.
}

\author{
Luiz A. Magalhães
}

o autor estuda os dados obtidos pela infecção de moluscos de Campinas $e$ de Belo Horizonte por miracídios de $\mathrm{S}$. mansoni. Chega à conclusão de que a população de Belo Horizonte mostrou-se mais susceptivel à infeccão pelo helminto do que a populaçâa de moluscos de Campinas.

\section{INTRODUÇÃO}

Creio ter ficado comprovado que a resistência apresentada por moluscos transmissores da esquistossomose mansônica à infecção pelo helminto não está apenas relacionada com o problema de ser o miracídio infectante proveniente de trematódeo oriundo de cêpa mantida por outra espécie de molusco.

Parece-me que, eventualmente, as variaçōes inter-específicas apresentadas nos genotipos dos moluscos, também conccrrem para o grau de suscetibilidade à infeç̧ão dos planorbídeos pelo $S$. mansoni $(1,2)$.

Neste trabalho estuda-se a resistência apresentada pelos moluscos de Campinas à infecção pelo $S$. mansoni oriundo do $\mathrm{Va}$ le do Rio Paraíba, onde é êste helminto mantido por moluscos da mesma espécie do campineiro ( $B$. tenagophila) .

Comparam-se os resultados com os apresentadcs por uma população de $B$. glabrata de Belo Horizonte infectada por S. mansoni oriunda da mesma cidade.

\section{MÉTODOS}

Utilizaram-se na experiência 60 moluscos de diâmetro máximo entre 8 a 10 milímetros. Os moluscos foram infectados, cada um, por 10 miracídios provenientes das cepas utilizadas na experiência.

Após 30 dias a contar da data da in.fecção dos moluscos, êles eram examinados diàriamente para verificação da eliminação de cercárias. Diàriamente, eram também separados os planorbídeos mortos, esmagados entre duas placas de vidro e examinadcs à lupa estereoscópica para procura de cercárias ou esporocistos. Após 60 dias a contar da data do início da experiência, todos os planorbídeos foram sacrificados e esmagados entre duas placas de vidro e levados à lupa para procura de espcrocistos e cercárias.

\section{RESULTADOS}

Os resultados estão contidos na tabela abaixo: 


\begin{tabular}{|l|c|c|}
\hline CEPA & BH & SJ \\
\hline n" de miracídios & 10 & 10 \\
n' de moluscos & 30 & 30 \\
moluscos infectados após 60 dias & 29 & 12 \\
dia da eclosão das cercárias & $42^{\prime \prime}$ & $42^{\prime \prime}$ \\
moluscos vivos após 60 dias & 21 & 6 \\
\hline
\end{tabular}

Calculado o índice de infecçāo verificou-se que era de $96,5 \%$ para a população de Belo Horizonte e de $40 \%$ para a de Campinas.

$O$ indice de mortalidade foi de $27,5 \%$ para a população mineira e de $50 \%$ para a campineira.

O período de desenvolvimento dos esporccistcs foi presumivelmente o mesmo, pois em ambas as populações as cercárias foram observadas pela primeira vez no 42 dia.

\section{DISCUSSÃO E CONCLUSÃO}

A população de $B$. glabrata proveniente de Bela Horizonte suporta melhor a infecção pelo $S$. mansoni (IM $=27,5 \%$ ) do que a populaçãc de $B$. tenagophila de Campinas infectada pelo $S$. mansoni de
São José dos Campos (IM =- $50 \%$ ).

A população de Belo Horizonte mostrou-se mais suscetível à infecção pelo $S$. mansoni lccal (II $=96,5 \%$ ) do que a população de $B$. tenagophila de Campinas à cêpa de $S$. mansoni de São José dos Campos (II $=:-40 \%$ ).

O período de desenvolvimento das larvas de $S$. mansoni nos moluscos das duas espécies, foi presumivelmente o mesmo (42 dias).

Conclui-se que dentre os moluscos das duas populações estudadas sob as condições em que a experiência foi realizada, a população de B. glabrata comportou-se como melhor hcspedeira da cêpa de $S$. mansoni da mesma cidade do que a população de $B$. tenagophila de Campinas submetida à infecção pelo $S$. manšoni de Săo José dos Campos.

\section{SUMMARY}

The author studied data obtained with the infection of Campinas and Beio Horizonte snails by $\mathrm{S}$. mansoni miracidia. He concludes that Belo Horizonte snail population is more susceptible to this infection than the Campinas pcpulation.

\section{BIBLIOGRAFIA}

1... MAGALHÃES, L. A. - Moluscos plancrbídeos do Distrito Federal, Brasilia. Tese apresentada à Universidade de Campinas, São Paulo, 1966
2 - PARAENSE, W. L. \& CORRÊ, L. R. - Susceptibility of Australorbis tenagophilus to infection with Schistosoma mansoni. Rev. Ins. Med. Trop. S. Paulo 5(1) : 23-29, 1963 